\title{
Thrombotic genetic risk factors and warfarin pharmacogenetic variants in São Miguel's healthy population (Azores)
} Claudia C Branco ${ }^{\dagger 1,2}$, Tânia Pereirinha ${ }^{\dagger 1}$, Rita Cabral ${ }^{1,2}$, Paula R Pacheco ${ }^{1,2}$ and Luisa Mota-Vieira*1,2

Address: ${ }^{1}$ Molecular Genetics and Pathology Unit, Hospital of Divino Espirito Santo of Ponta Delgada, EPE, São Miguel Island, Azores, Portugal and 'Instituto Gulbenkian de Ciência, Oeiras, Portugal

Email: Claudia C Branco - claudiacbranco@hdes.pt; Tânia Pereirinha - taniapereirinha@hdes.pt; Rita Cabral - ritacabral@hdes.pt; Paula R Pacheco - paularpacheco@hdes.pt; Luisa Mota-Vieira* - Imotavieira@hdes.pt

* Corresponding author †Equal contributors

Published: 18 June 2009

Thrombosis Journal 2009, 7:9 doi:10.1 186/1477-9560-7-9
Received: 5 December 2008

Accepted: 18 June 2009

This article is available from: http://www.thrombosisjournal.com/content/7/1/9

(C) 2009 Branco et al; licensee BioMed Central Ltd.

This is an Open Access article distributed under the terms of the Creative Commons Attribution License (http://creativecommons.org/licenses/by/2.0), which permits unrestricted use, distribution, and reproduction in any medium, provided the original work is properly cited.

\begin{abstract}
Summary
Background: The Azorean population presents the highest standardized mortality rate for cardiovascular diseases (CVD) when compared to mainland Portugal and other populations. Since thrombosis is a common cause of CVD, we assessed four polymorphisms in three thrombotic risk genes - F5 (GI69IA), F2 (G202I0A) and MTHFR (C677T, AI298C), in 469 healthy blood donors from São Miguel Island (Azores). We also analysed the CYP2C9 (C430T, A 1075C) and VKORCI (GI639A) variants in fifty-eight individuals with predisposition to thrombosis (possessing at least one variation in $F 5$ or $F 2$ genes and one in MTHFR) to evaluate their warfarin drug response genetic profiles.
\end{abstract}

Results: Among the 469 individuals, the data showed that thrombotic risk allele frequencies I69IA (4.9\%), 20210A (I.8\%), 677T (4I.7\%) and 1298C (24.8\%) - were similar to other Caucasians, but significantly different from mainland Portuguese $\left(\chi^{2}, p<0.001\right)$. The combined analysis of these variants identified twenty-two different genetic profiles (genotype order: $F 5, F 2$, MTHFR C677T and AI298C). Complete homozygosity for all wild-type alleles (GG GG CC AA) was present in $11.7 \%$, being GG GG CT AA (22.4\%) the most frequent profile. The results also demonstrated that $12.4 \%$ (58 out of 469 ) of São Miguel islanders have increased genetic predisposition to thrombosis. Subsequently, we evaluated these individuals for their warfarin response genetic profiles. The data showed that seven out of fifty-eight individuals are poor metabolizers (two with CYP2C9*2/*2 and five with CYP2C9*2/*3 genotypes). VKORCI polymorphism analysis identified twelve individuals $(20.7 \%)$ with AA genotype, who probably will require lower doses of warfarin. The joint analysis of CYP2C9 and VKORCI revealed that 79.3\% (46 out of 58) of the individuals carry at least one polymorphism in these genes. Within these, twentyfive individuals (43.1\%) need intermediate and/or low doses of warfarin, if treatment is started.

Conclusion: The present study demonstrated, for the first time, that São Miguel, and possibly the Azores population, shows significant differences on allele frequencies of thrombotic risk factors when compared to mainland Portugal. This research constitutes a primary approach for future studies on CVD, as well as for the implementation of warfarin dosing protocols using the patient's genotypic information. 


\section{Background}

Cardiovascular diseases (CVD) are complex disorders that include dysfunctional conditions of the heart, arteries and veins. Within these diseases, thrombosis is the third most common cardiovascular event worldwide [1]. It can derive from: i) genetic factors; ii) acquired changes in the clotting mechanism; and iii) more commonly, interaction between the two factors described above [2-4]. The main hereditary form of thrombosis is caused by the G1691A variation in the factor $\mathrm{V}$ Leiden gene $(F 5 ; 1 \mathrm{q} 23)$, resulting in resistance to activated protein C (APC). In the coagulation biochemical pathway, APC prevents blood clots from growing extensively large, by inactivating coagulation factor $\mathrm{V}$ (encoded by F5). The G1691A variation may increase the risk for thrombosis by 8 and 91 in heterozygous and homozygous states, respectively [5]. According to Poort et al. [6], prothrombin (F2; 11p11-q12) represents the second most important inherited thrombotic risk factor. A single base substitution (G20210A) in the F2 3'-untranslated region causes elevated plasma prothrombin levels. The same authors reported a 2.8 -fold increase risk for venous thrombosis in heterozygous and homozygous variant individuals [6]. Other reported gene involved in thrombosis, the methylenetetrahydrofolate reductase (MTHFR; 1p36.3), includes two variants C677T and A1298C [7]. The 677T alters the protein's folate binding site and lowers the enzymatic activity of MTHFR. As consequence, patients have elevated plasma levels of total homocysteine (tHcy) [8]. The 1298C variant also decreases the enzymatic activity of MTHFR, which is more pronounced in homozygous variant than in heterozygous state [8]. According to Heijer et al. [9], individuals with the 677TT genotype show a $15 \%(\mathrm{OR}=1.1 ; 95 \% \mathrm{CI}$ $=1.0-1.3)$ increased risk for venous thromboembolism (VTE) in Europe. Additionally, Klerk et al. [10] reported an OR of $1.3(95 \% \mathrm{CI}=1.1-1.5)$ for the 677CT genotype.

The genetic characterization of the individual's potential risk for developing thrombosis and response to drugs is essential in clinical follow-ups, as well as for medical prescription. Warfarin is one of the most widely used anticoagulant drug, which requires a thorough risk-benefit analysis since the dose prescribed should avoid hemorrhagic complications and achieves suppression of thrombosis [11]. The administrated drug is a racemic mixture of $\mathrm{S}$ - and R-enantiomers, having S- the majority of the therapeutic effect [12]. Warfarin pharmacogenetic studies demonstrated that variants in the CYP2C9 (Cytochrome P450 2C9) and VKORC1 (Vitamin K epoxide reductase complex subunit 1) genes account for approximately $50-60 \%$ of drug dosing variability $[13,14]$. Cytochrome P450 2C9 is the major enzyme responsible for metabolising the active S-enantiomer [12]. Although there are many polymorphisms in CYP2C9, the most frequent variants are: CYP2C9*1 (Arg144/Ile359, wild-type), CYP2C9*2
(Arg144Cys) and CYP2C9*3 (Ile359Leu). These last two are associated with decreased metabolic efficiency of the CYP2C9 enzyme and increased risk of bleeding when administrated initial dosages of warfarin [15]. A G $>$ A variation at position 1639 in the promoter region of the VKORC1 gene results in decreased mRNA transcription and increased sensitivity to warfarin inhibition of hepatic synthesis of functional vitamin K-dependent coagulation factors [13]. Rieder et al. [13] studied VKORC1 polymorphisms and classified individuals according to warfarin dose requirements into distinct groups: high (GG), intermediate (GA) and low (AA).

The Azores population presents the highest standardized mortality rate caused by CVD when compared to mainland Portugal (Portuguese General Directorate of Health) [16] and other populations. Since thrombosis is a known cause of CVD, the present research aims to assess, in the São Miguel healthy population, the allelic variants and genotypes of three genes - F5, F2 and MTHFR - involved in blood clot formation. Moreover, in the individuals with predisposition to thrombosis, we evaluated the pharmacogenetic profile for warfarin, by characterizing CYP2C9 and VKORC1 polymorphisms. This information is important for the implementation of warfarin pre-prescription genotyping with the goal of performing individualized treatment.

\section{Materials and methods Population sample}

The population sample comprised a group of 469 São Miguel Island blood donors from the anonymized Azorean DNA bank located in the main Hospital of Azores archipelago, Portugal [17]. São Miguel, the largest island in this archipelago, has 131,609 inhabitants $(54.4 \%$ of the Azoreans; 2001 Census, Portugal National Institute of Statistics) [18]. In this group we analysed four polymorphisms in three thrombotic predisposition genes - F5 (G1691A), F2 (G20210A) and MTHFR (C677T, A1298C). After evaluating the genetic variants in the aforementioned genes, we selected a subset of individuals who met one of the following criteria: 1. one variant in F5 and one in MTHFR (fourty-three individuals); 2. one variant in F2 and one in MTHFR (fifteen individuals) and 3. one variant in F5, F2 and MTHFR (zero individuals). These criteria were chosen to restrict the sample to individuals who would have a higher genetic risk for a thrombotic event, and hence fifty-eight individuals were analysed for CYP2C9 and VKORC1 polymorphisms.

\section{Genotyping of F5 and MTHFR polymorphisms}

F5 and MTHFR polymorphisms (Table 1) were evaluated by polymerase chain reaction - restriction fragment length polymorphism (PCR-RFLP), using three different restriction enzymes: MnlI, Hinfl and MboII (New England 
Table I: Main characteristics of the seven genetic variants analysed in this study

\begin{tabular}{|c|c|c|c|c|c|}
\hline \multirow[t]{2}{*}{ Polymorphism } & \multirow[t]{2}{*}{ Allele variant } & \multirow[t]{2}{*}{ Amino acid change } & \multicolumn{3}{|c|}{ Gene } \\
\hline & & & Location & Position & NCBI dbSNP rs\# \\
\hline Factor V Leiden & $|69| G>A$ & R506Q & $1 \mathrm{q} 23$ & Exon 10 & rs6025 \\
\hline Prothrombin & $20210 G>A$ & NA & ||$p||-q \mid 2$ & 3'-UTR & rsl799963 \\
\hline \multirow[t]{2}{*}{ MTHFR } & $677 \mathrm{C}>\mathrm{T}$ & $\mathrm{A} 222 \mathrm{~V}$ & Ip36.3 & Exon 5 & rs 1801133 \\
\hline & $1298 A>C$ & E429A & Ip36.3 & Exon 8 & rsl801131 \\
\hline CYP2C9*2 & $430 \mathrm{C}>\mathrm{T}$ & $\mathrm{R} I 44 \mathrm{C}$ & 10q24.1 & Exon 3 & rs|799853 \\
\hline CYP2C9*3 & $1075 A>C$ & 1359L & $10 q 24.1$ & Exon 7 & rs1057910 \\
\hline VKORCI & $1639 G>A$ & NA & $16 p \mid 1.2$ & Promoter & rs9923231 \\
\hline
\end{tabular}

NA - not applicable; UTR - untranslated region.

Biolabs, Beverly, MA, USA). The genotyping protocol for the detection of the F5 polymorphism and MTHFR variants was adapted from Kumar et al. [19] and Skibola et al. [20], respectively.

Genotyping of F2, CYP2C9 and VKORCI polymorphisms The genetic tests used for F2, CYP2C9 and VKORC1 (Table 1) were PTH StripAssay ${ }^{\mathrm{TM}}$ and PGX-Thrombo StripAssay ${ }^{\mathrm{TM}}$ kits (ViennaLab-Labordiagnostika GmbH-Austria), according to the manufacturer's recommendations. These assays are based on reverse hybridization system, using biotin-labelled amplification products to a parallel array of allele-specific oligonucleotides immobilized on a membrane test strip.

\section{Statistical Analysis}

Allele frequencies were obtained by direct count. HardyWeinberg equilibrium was calculated using the Arlequin software v.3.20. This software was used to assess maximum likelihood genetic profiles for thrombotic risk factors, through the expectation maximization algorithm, an iterative procedure from multilocus genotype data with unknown gamete phase. Allele and genotype frequencies were compared between São Miguel islanders and mainland Portuguese by $\chi^{2}$ test using the SPSS software v.17.0. A $p<0.05$ was considered statistically significant.

\section{Results \\ Allele and genotype frequencies of thrombotic genetic risk factors}

Allele and genotype frequencies of F5 (G1691A), F2 (G20210A) and MTHFR (C677T, A1298C) polymorphisms were assessed in 469 healthy individuals from São Miguel Island, Azores (Table 2). All markers were in Hardy-Weinberg equilibrium. The F5 variant 1691A frequency was $4.9 \%$, whereas the heterozygous genotype (1691GA) was present at 9.8\% (fourty-six individuals). We did not detect 1691AA individuals. The results on the F2 analysis show an allele frequency of $1.8 \%$ for the 20210 A variant. Although this polymorphism is also uncommon in other populations, one homozygous variant individual $(0.2 \%)$ and fifteen heterozygous $(3.2 \%)$ were observed in the present study. The frequency of the variant alleles in MTHFR (677T and 1298C) was 41.7 and $24.8 \%$, respectively. Overall, $17.9 \%$ are $677 \mathrm{TT}$ (eightyfour individuals), and $6.0 \%$ present the 1298CC genotype (twenty-eight individuals).

Twenty-two different genetic profiles for F5, F2 and MTHFR (order in genotype profile) were observed in São Miguel's population (Figure 1). The frequency of individuals who present a wild-type genotype for all polymorphisms (GG GG CC AA; 11.7\%) was almost half of the major profile (GG GG CT AA; 22.4\%), differing in heterozygosity for MTHFR 677CT. Statistical analysis of the combined genotypes demonstrated that there is no significant difference between the present distribution and the hypothetical obtained by Arlequin software $\left(\chi^{2}, p=0.99\right)$. No heterozygous or homozygous profiles for all four variants were observed. Almawi et al. [21], reported an OR of $10.5(95 \% \mathrm{CI}=4.3-25.3)$ or $6.3(95 \% \mathrm{CI}=1.5-26.0)$ for joint occurrence of the F5 G1691A or F2 G20210A with MTHFR 677TT genotype, respectively, enhancing the risk for deep vein thrombosis (DVT). Based on this criterion, fifteen (3.2\%, F5/MTHFR) and two individuals (0.4\%, F2/ MTHFR) have higher risk for DVT development (Figure 1 - asterisk character; Table 3 - bold characters). In general, the joint analysis of all four variants demonstrated that $12.4 \%$ of the total sample (58 out of 469 ) has increased predisposition to thrombosis development.

The comparison of allele frequencies of the thrombotic genetic risk factors - F5, F2 and MTHFR - in different populations, including São Miguel, is depicted in Figure 2[6,22-38]. F5 G1691A varies from as low as $0.67 \%$ (African-American) to $4.9 \%$ (São Miguel Island). This trend is not evident for F2 G20210A, where the values present a lower range, from $0.3 \%$ for African-American to $2.6 \%$ for Spanish. African populations showed the lowest frequency for MTHFR variants. Taken together, the results 
Table 2: Allele and genotype frequencies for thrombotic risk factors and for warfarin pharmacogenetic variants in São Miguel population

\begin{tabular}{|c|c|c|c|c|c|c|}
\hline Polymorphism & Allele & $\mathrm{n}^{\mathrm{a}}$ & Freq. & Genotype & $\mathrm{n}^{\mathrm{b}}$ & Freq. \\
\hline \multicolumn{7}{|c|}{ Thrombotic risk variants in general population $(N=469)$} \\
\hline \multicolumn{7}{|c|}{ Factor V Leiden } \\
\hline \multirow[t]{3}{*}{$1691 \mathrm{G}>\mathrm{A}$} & G & 892 & 0.951 & GG & 423 & 0.902 \\
\hline & A & 46 & 0.049 & GA & 46 & 0.098 \\
\hline & & & & AA & 0 & 0.000 \\
\hline \multicolumn{7}{|l|}{ Prothrombin } \\
\hline \multirow[t]{3}{*}{$20210 \mathrm{G}>\mathrm{A}$} & G & 921 & 0.982 & GG & 453 & 0.966 \\
\hline & A & 17 & 0.018 & GA & 15 & 0.032 \\
\hline & & & & AA & 1 & 0.002 \\
\hline \multicolumn{7}{|l|}{ MTHFR } \\
\hline \multirow[t]{3}{*}{$677 C>T$} & C & 547 & 0.583 & $\mathrm{CC}$ & 162 & 0.345 \\
\hline & $\mathrm{T}$ & 391 & 0.417 & $\mathrm{CT}$ & 223 & 0.475 \\
\hline & & & & $\mathrm{TT}$ & 84 & 0.179 \\
\hline \multirow[t]{3}{*}{$1298 \mathrm{~A}>\mathrm{C}$} & A & 705 & 0.752 & $A A$ & 264 & 0.563 \\
\hline & C & 233 & 0.248 & $A C$ & 177 & 0.377 \\
\hline & & & & $\mathrm{CC}$ & 28 & 0.060 \\
\hline \multicolumn{7}{|c|}{ Warfarin pharmacogenetic variants in individuals with predisposition to thrombosis $(\mathbf{N}=\mathbf{5 8})$} \\
\hline \multicolumn{7}{|c|}{ CYP2C9 } \\
\hline \multirow[t]{3}{*}{$430 \mathrm{C}>\mathrm{T}^{\mathrm{c}}$} & C & 98 & 0.845 & $*|/ *|$ & 35 & 0.603 \\
\hline & $\mathrm{T}$ & 18 & 0.155 & $* 1 / * 2$ & 9 & 0.155 \\
\hline & & & & $* 2 / * 2$ & 2 & 0.035 \\
\hline \multirow[t]{3}{*}{$1075 \mathrm{~A}>\mathrm{Cc}$} & A & 104 & 0.897 & $* 1 / * 3$ & 7 & 0.121 \\
\hline & C & 12 & 0.103 & $* 2 / * 3$ & 5 & 0.086 \\
\hline & & & & $* 3 / * 3$ & 0 & 0.000 \\
\hline \multicolumn{7}{|l|}{ VKORCI } \\
\hline \multirow[t]{3}{*}{$1639 G>A$} & G & 66 & 0.569 & GG & 20 & 0.345 \\
\hline & A & 50 & 0.431 & GA & 26 & 0.448 \\
\hline & & & & $A A$ & 12 & 0.207 \\
\hline
\end{tabular}

a Number of chromosomes

b Number of alleles

c*l*I (430CC/I075AA), *I*2 (430CT/I075AA), *I*3 (430CC/I075AC), *2*2 (430TT/I075AA), *2*3 (430CT/I075AC) and *3*3 (430CC/1075CC)

demonstrate that, in São Miguel, the frequencies for all polymorphisms were similar to those found in Caucasians.

\section{Frequencies of pharmacogenetic variants in individuals with genetic predisposition to thrombosis}

In order to understand warfarin pharmacogenetic profile in the fifty-eight individuals, carriers of at least one variation in F5 or F2 genes and one in MTHFR, we studied CYP2C9 and VKORC1 gene polymorphisms. The allele frequencies for CYP2C9*2 and CYP2C9*3 were 15.5 and $10.3 \%$, respectively (Table 2 ). Five genotypes were observed: $\quad$ CYP2C9*1/*1 (60.3\%), CYP2C9*1/*2 (15.5\%), CYP2C9*1/*3 (12.1\%), CYP2C9*2/*2 (3.5\%) and $\mathrm{CYP} 2 \mathrm{C} 9 * 2 /{ }^{*} 3(8.6 \%)$. The data indicate that $39.7 \%$ will require intermediate and/or low warfarin maintenance doses. Regarding the VKORC1 gene (G1639A), we identified twenty (34.5\%) wild-type individuals, twentysix (44.8\%) heterozygous and twelve (20.7\%) homozygous variant, corresponding to an allele frequency of $43.1 \%$ for 1639 A (Table 2 ). These results suggest that $65.5 \%$ need intermediate and/or low doses of warfarin.

The majority of individuals with a genetic predisposition to thrombosis $(79.3 \%, 46$ out of 58 ) carry at least one polymorphism in the genes involved in the metabolism of warfarin (Table 3). Moreover, the joint analysis of CYP2C9 and VKORC1 identified a total of thirty-three (57\%) individuals that probably will require high doses of warfarin (genotypes: * $1 * 1-\mathrm{GG} \rightarrow$ twelve individuals, $* 1 * 1-\mathrm{GA} \rightarrow$ fourteen, *1*2-GG $\rightarrow$ four and $* 1 * 3-\mathrm{GG} \rightarrow$ three), and eight (13.8\%) will need lower doses (genotypes: * $1 * 2-\mathrm{AA} \rightarrow$ one individual, $* 1 * 3-\mathrm{AA} \rightarrow$ one, ${ }^{*} 2 * 2$ - 


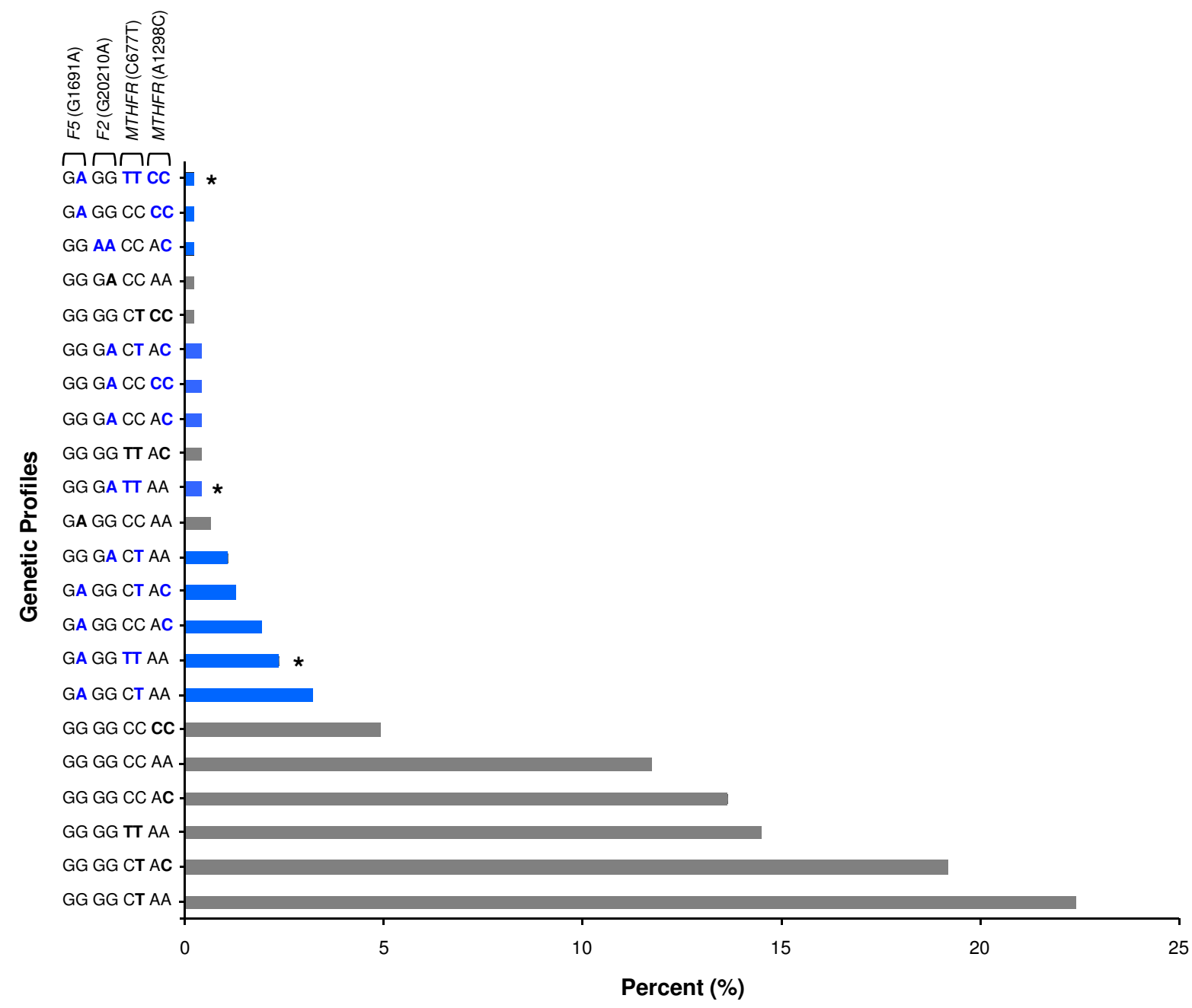

\section{Figure I}

Combined genotypes for thrombotic risk factors - F5, F2 and MTHFR - in São Miguel population. Twenty-two different genetic profiles were obtained. Bold characters (blue and black) indicate nucleotide changes compared to the wild-type allele. The asterisk (*) represents the combination of the F5 GI69IA or F2 G202 I0A with MTHFR 677TT genotype. Blue bars correspond to the subset of fifty-eight individuals with genetic predisposition to thrombosis selected for warfarin pharmacogenetic study.

$\mathrm{GA} \rightarrow$ two, $* 2 * 3-\mathrm{GA} \rightarrow$ one and $* 2 * 3-\mathrm{AA} \rightarrow$ three $)$. The remaining seventeen individuals $(29.3 \%)$ present one of the following genotypes: ${ }^{*} 1 * 1-\mathrm{AA} \rightarrow$ nine individuals, $* 1 * 2-\mathrm{GA} \rightarrow$ four, $* 1 * 3-\mathrm{GA} \rightarrow$ three and $* 2 * 3-\mathrm{GG} \rightarrow$ one, where all of them will possibly necessitate intermediate doses. In summary, twenty-five individuals (43.1\%) will need intermediate and/or low doses of warfarin, if treatment is started.

\section{Discussion}

In the general population, individuals may develop thrombosis due to multiple risk factors, acquired and genetic. Clearly, acquired factors (smoking, high cholesterol, obesity, etc.) are more frequent and combined with a genetic predisposition further enhance the risk of a thrombotic event. In the present study, the results obtained from 469 São Miguel healthy individuals demonstrate that approximately 5\% have the F5 1691A allele, the most common hereditary risk factor. Although the frequency found for São Miguel is higher than mainland Portuguese, 1\% [22], we did not detect homozygous variant individuals. Nonetheless, the data suggest that São Miguel islanders have an increased predisposition to thrombosis and, most probably for CVD. Another inherited cause of thrombosis is the G20210A polymorphism in the F2 gene. According to Bosler et al. [39], this variant is weak but a consistent risk factor for DVT and for development of CVD, although to a lesser degree than F5 [4]. The F2 
Table 3: Warfarin pharmacogenetic profile obtained in the fifty-eight individuals, carriers of at least one variation in $F 5$ or $F 2$ genes and one in MTHFR

\begin{tabular}{|c|c|c|c|c|c|c|c|}
\hline \multirow[b]{3}{*}{$\mathbf{N}(\%)$} & \multicolumn{4}{|c|}{ Thrombotic risk factors } & \multicolumn{3}{|c|}{ Warfarin pharmacogenetics } \\
\hline & F5 & F2 & MTHFR & & CYP2C9 & & VKORCI \\
\hline & $\mid 691 \mathrm{G}>\mathrm{A}$ & $20210 G>A$ & $677 \mathrm{C}>\mathrm{T}$ & $1298 \mathrm{~A}>\mathrm{C}$ & $430 \mathrm{C}>\mathrm{T}$ & $1075 A>C$ & $1639 G>A$ \\
\hline I ( 1.7$)$ & GA & GG & TT & AA & TT & AC & GA \\
\hline$I(1.7)$ & GA & GG & TT & AA & $\mathbf{C T}$ & $A C$ & $A A$ \\
\hline I (1.7) & $\mathrm{GA}$ & GG & $\mathrm{CC}$ & $A C$ & $C T$ & $A C$ & $\mathrm{GA}$ \\
\hline $2(3.5)$ & $\mathrm{GA}$ & GG & $\mathrm{CT}$ & AA & $C T$ & $A C$ & $\mathrm{G} A$ \\
\hline I (1.7) & $\mathrm{GA}$ & GG & $\mathrm{CC}$ & $A C$ & $\mathrm{CT}$ & $A C$ & GG \\
\hline $\mathrm{I}(1.7)$ & GG & $\mathrm{GA}$ & $\mathrm{CT}$ & $A C$ & $\mathrm{CC}$ & $A C$ & $A A$ \\
\hline I (I.7) & $\mathrm{GA}$ & GG & $\mathrm{CC}$ & $C C$ & $\mathrm{CC}$ & $A C$ & $\mathrm{GA}$ \\
\hline I (I.7) & $\mathrm{G} A$ & GG & $C T$ & $A C$ & $\mathrm{CC}$ & $A C$ & $\mathrm{GA}$ \\
\hline I (1.7) & GG & $\mathbf{G A}$ & $T T$ & AA & CC & $A C$ & GA \\
\hline I (I.7) & $\mathrm{G} A$ & GG & $\mathrm{CC}$ & $A C$ & $\mathrm{CC}$ & $A C$ & GG \\
\hline $2(3.5)$ & $\mathrm{GA}$ & GG & $C T$ & AA & $\mathrm{CC}$ & $A C$ & GG \\
\hline I (1.7) & $\mathbf{G A}$ & GG & $T T$ & CC & $T T$ & AA & GA \\
\hline I (I.7) & $\mathrm{GA}$ & GG & $C T$ & AA & $\mathrm{CT}$ & $\mathrm{AA}$ & $A A$ \\
\hline I (I.7) & $\mathrm{GA}$ & GG & $C T$ & $A C$ & $C T$ & $A A$ & $\mathrm{G} A$ \\
\hline I (1.7) & $\mathbf{G A}$ & GG & $T T$ & AA & $C T$ & AA & GA \\
\hline $2(3.5)$ & GG & $\mathrm{GA}$ & $C T$ & $A C$ & $C T$ & $A A$ & $\mathrm{G} A$ \\
\hline I (1.7) & GG & $\mathrm{G} A$ & $C T$ & $A A$ & $C T$ & $A A$ & GG \\
\hline $2(3.5)$ & $\mathrm{GA}$ & GG & $C T$ & AA & $C T$ & $A A$ & GG \\
\hline I (1.7) & GA & GG & $T T$ & AA & $C T$ & AA & GG \\
\hline $2(3.5)$ & $\mathrm{GA}$ & GG & $\mathrm{CC}$ & $A C$ & $\mathrm{CC}$ & $A A$ & $A A$ \\
\hline I (I.7) & $\mathrm{GA}$ & GG & $\mathrm{CT}$ & AA & $\mathrm{CC}$ & $A A$ & $A A$ \\
\hline $3(5.2)$ & GA & GG & $T T$ & AA & CC & AA & $A A$ \\
\hline I (1.7) & GG & $\mathrm{GA}$ & CC & $A C$ & $\mathrm{CC}$ & $A A$ & $A A$ \\
\hline I (I.7) & GG & $\mathrm{GA}$ & $\mathrm{CT}$ & $A C$ & $\mathrm{CC}$ & $A A$ & $A A$ \\
\hline I (1.7) & GG & $\mathbf{G A}$ & $T T$ & AA & CC & AA & $A A$ \\
\hline $2(3.5)$ & $\mathrm{GA}$ & GG & $\mathrm{CC}$ & $A C$ & $\mathrm{CC}$ & $A A$ & $\mathrm{GA}$ \\
\hline I (1.7) & $\mathrm{GA}$ & GG & $\mathrm{CT}$ & AA & $\mathrm{CC}$ & $A A$ & $\mathrm{GA}$ \\
\hline $2(3.5)$ & $\mathrm{GA}$ & GG & $C T$ & $A C$ & CC & $A A$ & $\mathrm{G} A$ \\
\hline $4(6.9)$ & $\mathbf{G A}$ & GG & $T T$ & AA & CC & AA & $\mathbf{G A}$ \\
\hline I (I.7) & GG & $A A$ & $\mathrm{CC}$ & $A C$ & $\mathrm{CC}$ & $A A$ & $\mathrm{GA}$ \\
\hline I (1.7) & GG & $\mathrm{G} A$ & $\mathrm{CC}$ & $A C$ & $\mathrm{CC}$ & $A A$ & $\mathrm{GA}$ \\
\hline I (1.7) & GG & $\mathrm{G} A$ & $\mathrm{CC}$ & $C C$ & $\mathrm{CC}$ & $A A$ & $\mathrm{GA}$ \\
\hline $2(3.5)$ & GG & $\mathrm{GA}$ & $C T$ & AA & $\mathrm{CC}$ & $A A$ & $\mathrm{GA}$ \\
\hline $2(3.5)$ & $\mathrm{G} A$ & GG & CC & $A C$ & $\mathrm{CC}$ & $A A$ & GG \\
\hline $3(5.2)$ & $\mathrm{GA}$ & GG & $\mathrm{CT}$ & AA & $\mathrm{CC}$ & $A A$ & GG \\
\hline $2(3.5)$ & $\mathrm{GA}$ & GG & $C T$ & $A C$ & $\mathrm{CC}$ & $A A$ & GG \\
\hline I (I.7) & GG & $\mathrm{GA}$ & $\mathrm{CC}$ & $C C$ & $\mathrm{CC}$ & AA & GG \\
\hline I (I.7) & GG & $\mathrm{GA}$ & $C T$ & AA & $\mathrm{CC}$ & $A A$ & GG \\
\hline $3(5.2)$ & $\mathbf{G A}$ & GG & $T T$ & AA & CC & AA & GG \\
\hline
\end{tabular}

Italic characters indicate nucleotide changes considering the wild-type allele and in bold illustrate carriers of the F5 GI69IA or F2 G202 I0A with MTHFR 677TT genotype conferring high thrombotic risk.

results show a lower frequency, $1.8 \%$, when compared to mainland Portugal, $2.5 \%[22]$.

The most general form of genetic hyperhomocysteinemia results from the MTHFR C677T variant, which has a relatively high frequency throughout the world and is considered a low risk factor for vascular diseases [9]. In São Miguel population, MTHFR 677T shows an allelic frequency of $41.7 \%$, very similar to Europeans (Figure 2).
According to Almawi et al. [21], MTHFR 677TT genotype when associated with $F 5$ or F2 increases the risk of DVT [20]. Based on these genotypes, the data suggests that $3.6 \%$ (seventeen individuals) of the São Miguel Island population may have higher risk for developing a thrombotic event. Regarding the $1298 \mathrm{C}$ variant, the results were in agreement with those reported by other studies (Figure 2 ), where the polymorphism is also common. We can hypothesise that if the 1298CC individuals have higher 

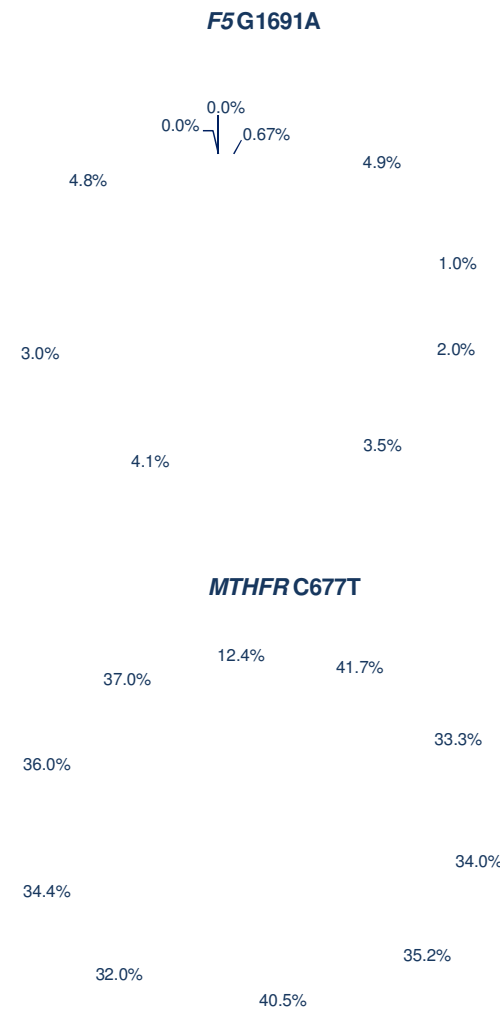
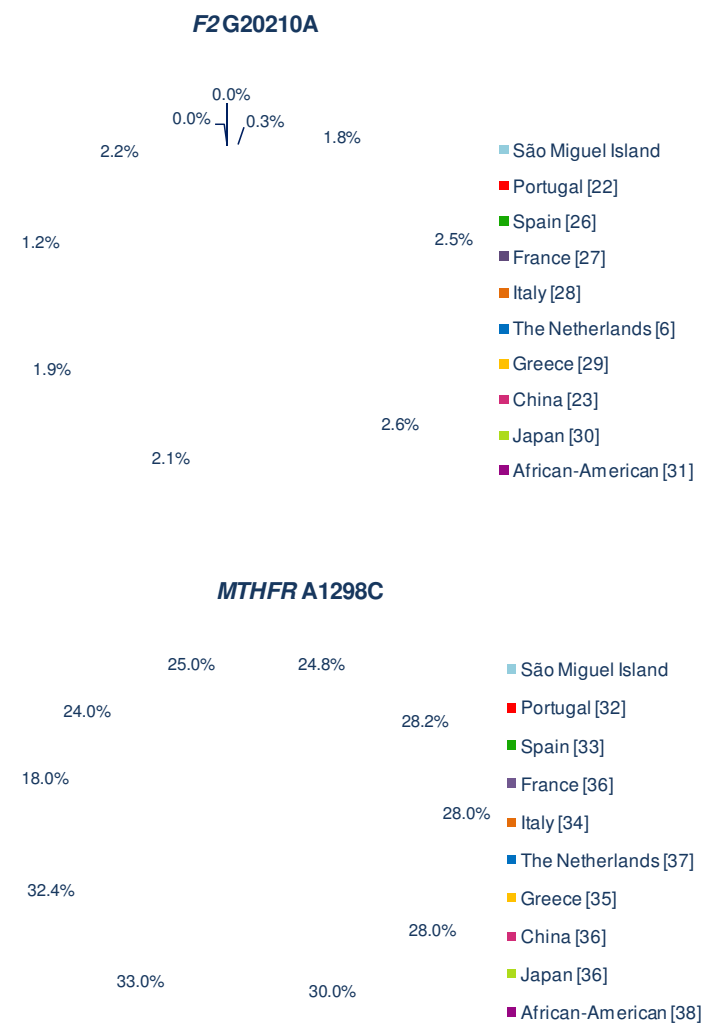

\section{Figure 2 \\ Allele frequencies of the thrombotic risk factors - F5 (G I 69 I A), F2 (G202 I 0A) and MTHFR (C677T, A I 298C) - in different populations, including São Miguel.}

plasma homocysteine levels, they will present an enhanced risk for thrombosis.

The joint analysis of all variants demonstrated that $12.4 \%$ of the total sample (58 out of 469) has increased predisposition to thrombosis development. In addition, comparison of allele frequencies for all thrombotic risk factors between São Miguel and mainland Portugal revealed statistically significant differences $\left(\chi^{2}, p<0.001\right)$. Familybased investigation tends to have biased relative risk estimation, because oversampling of affected individuals is normally present. Therefore, the genetic characterization of disease variants in the general population is important to correct this potential bias. Consequently, the present research will aid the clinical follow-ups of patients with recurrent thrombotic events.

In today's medicine, the association between pharmacogenetics and drug therapy represents an important tool to treat or control complex diseases. Drug treatment is based on the assumption that a particular dose will yield a predefined blood concentration in circulation and, thereby, establish the desired therapeutic effect [40]. Recent investigations clearly demonstrate an association between warfarin dose requirements and genetic variations in CYP2C9 and VKORC1 [14]. Here, we analysed 58 individuals with genetic predisposition to thrombosis defined by at least one variation in F5 or F2 genes and one in MTHFR. The results obtained show that approximately $60.3 \%$ present the genotype CYP2C9* $1 /{ }^{*} 1$, while the remaining have CYP2C9*2 and CYP2C9*3 variants. The presence of two copies of the active CYP2C9* 1 alleles represents the normal metabolic capacity - extensive metabolizers (EMs) -, indicating that individuals with this genotype require the highest warfarin maintenance doses [41].

Considering São Miguel islanders with genetic predisposition to thrombosis, the data of CYP2C9*2 and CYP2C9*3 alleles demonstrate a close similarity with different European populations [42-44]. Individuals who are hetero- 
zygous $\left(\mathrm{CYP} 2 \mathrm{C} 9 * 1 /{ }^{*} 2\right.$ and $\left.C Y P 2 C 9 * 1 /{ }^{*} 3\right)$ represent a middle range of metabolic activity - intermediate metabolizers, IMs $[43,44]$. The results reveal that, within the fifty-eight subset, 15.5 and $12.1 \%$ are IMs, respectively. The CYP2C9*2 and CYP2C9*3 variants have less activity and metabolize warfarin more slowly. Individuals with one or two of these variations - poor metabolizers (PMs) - have an enhanced response to warfarin, as well as an increased risk of bleeding when beginning and during treatment if not genotyped previously [44]. We observed that seven out of fifty-eight individuals are PMs (two with CYP2C9*2/*2 and five with $\mathrm{CYP} 2 \mathrm{C} 9 * 2 /{ }^{*} 3$ genotypes; Table 2). Detecting genetic variations in drug-metabolizing enzymes is useful for identifying individuals who may experience adverse drug reactions (ADRs) with conventional medication doses. Those who are CYP2C9 PMs may exhibit different pharmacokinetics than wild-type individuals if they are medicated with warfarin. Consequently, these individuals possibly will require nonconventional doses of drugs that need CYP2C9 enzyme for biotransformation [45].

Polymorphisms within VKORC1, a target of warfarin inhibition, may explain 23\% of this drug dosage variability [13]. Rieder and colleagues [13] divided individuals into warfarin high-dose for 1639GG genotype, intermediatedose for 1639GA and low-dose for 1639AA. This variability is attributed to the fact that the variant lies within the VKORC1 promoter, potentially resulting in decreased transcription of the gene product. In general, the results suggest that $65.5 \%$ of the fifty-eight individuals with predisposition to thrombosis will require intermediate and/ or low doses of warfarin, if treatment is started. Personalized medicine relies on data based on the human genome and disease biology characterization for the development of preventive, diagnostic, and therapeutic strategies that target the underlying determinants of disease in populations with specific molecular profiles [46]. For this reason, the knowledge obtained from the pharmacogenetic profile in the São Miguel's general population is and will be important for the development of patient's individualized therapy, mainly for those who have difficulty to stabilize the warfarin dose.

\section{Conclusion}

The identification of hereditary risk factors, with appropriate clinical evaluation will allow the informed patient and physician to work together for effective management of thrombosis and prevention of subsequent thrombotic events. The present study demonstrated, for the first time, that São Miguel, and possibly the Azores population, shows significant differences on allele frequencies of thrombotic genetic risk factors when compared to mainland Portugal. This research constitutes a primary approach for future studies on CVD, as well as for the implementation of warfarin dosing protocols using the patient's genotypic information.

\section{Abbreviations}

ADRs: Adverse drug reactions; APC: Activated protein C; $\mathrm{CI}$ : Confidence interval; CVD: Cardiovascular diseases; CYP2C9: Cytochrome P450 2C9 gene; DVT: Deep vein thrombosis; EMs: Extensive metabolizers; F2: Prothrombin gene; F5: Factor V Leiden gene; IMs: Intermediate metabolizers; MTHFR: Methylenetetrahydrofolate reductase gene; OR: Odds Ratio; PCR-RFLP: Polymerase chain reaction - restriction fragment length polymorphism; PMs: Poor metabolizers; SNP: Single nucleotide polymorphism; tHcy: Total homocysteine; VKORC1: Vitamin $\mathrm{K}$ epoxide reductase complex subunit 1 gene; VTE: Venous thromboembolism.

\section{Competing interests}

The authors declare that they have no competing interests.

\section{Authors' contributions}

CCB and TP, contributed equally, by performing the experiments, statistical analysis and drafting the manuscript. RC genotyped MTHFR variants and PRP participated in the analysis. LMV designed the study, provided scientific orientation and revised the manuscript. All authors read and approved the final manuscript.

\section{Acknowledgements}

This work was supported by grants from Direcção Regional da Ciência e Tecnologia of Azores (Ref. MI.2.1///002/2008). PRP is funded by grant (Ref. SFRH/BD/27453/2006) from Fundação para a Ciência e a Tecnologia of Portugal.

\section{References}

I. Menon J, Salman MM, Md GH: Venous thrombolysis: Current perspectives. Curr Treat Options Cardiovasc Med 2004, 6: I 59-I68.

2. World Health Organization: Cardiovascular disease: prevention and control (WHO Global Strategy on Diet, Physical Activity and Health). Recommendations from a Joint Study Group 2008 [http://www.who.int/en/].

3. Rosendaal FR: Venous thrombosis, a multicausal disease. Lancet 1999, 353:1167-II73.

4. Khan S, Dickerman JD: Hereditary thrombophilia. Thromb J 2006, 4:I-I7.

5. Bertina RM, Reitsma RH, Rosendaal FR, Vandenbroucke JP: Resistance to activated protein $\mathbf{C}$ and factor $\mathbf{V}$ Leiden as risk factors for venous thrombosis. Thromb Haemost I995, 74:449-553.

6. Poort SR, Rosendaal FR, Reitsma PH, Bertina RM: A common genetic variation in the 3 '-untranslated region of the prothrombin gene is associated with elevated plasma prothrombin levels and an increase in venous thrombosis. Blood 1996, 88:3698-3703.

7. Varga EA, Sturm AC, Misita CP, Moll S: Homocysteine and MTHFR mutations. Relation to thrombosis and coronary artery disease. Circulation 2005, I I I :e289-e293.

8. Almawi WY, Ameen G, Tamim H, Finan RR, Irani-Hakime N: Factor V GI69IA, prothrombin G202IOA and methylenetetrahydrofolate reductase [MTHFR] C677T gene polymorphisms in angiographically documented coronary artery disease. J Thromb Thrombolysis 2004, I 7: 199-205.

9. Den Heijer M, Lewington S, Clarke R: Homocysteine, MTHFR and risk of venous thrombosis: a meta-analysis of published epidemiological studies. J Thromb Haemost 2005, 3:292-299. 
10. Klerk M, Verhoef P, Clarke R, Blom HJ, Kok FJ, Shouten EG: MTHFR 677C $>$ T polymorphism and risk of coronary heart disease. A meta-analysis. JAMA 2002, 288:2023-203I.

II. Scott SA, Edelmann L, Kornreich R, Desnick RJ: Warfarin pharmacogenetics: CYP2C9 and VKORCI genotypes predict different sensitivity and resistance frequencies in the Ashkenazi and Sephardi Jewish populations. Am J Hum Genet 2008, 82:495-500.

12. Rettie AE, Tai G: The pharmacogenomics of warfarin. Mol Interv 2006, 6:223-227.

13. Rieder MJ, Reiner AP, Gage BF, Nickerson DA, Eby CS, McLeod HL Blough DK, Thummel KE, Veenstra DL, Rettie AE: Effect of $V K O R C I$ haplotypes on transcriptional regulation and warfarin dose. $N$ Engl J Med 2005, 352:2285-2293.

14. Wadelius M, Chen LY, Downes K, Ghori J, Hunt S, Eriksson N, Wallerman O, Melhus H, Wadelius C, Bentley D, Deloukas P: Common VKORCI and GGCX polymorphisms associated with warfarin dose. Pharmacogenomics J 2005, 5:262-270.

15. Yasar Ü, Eliasson E, Dahl ML, Johansson I, Ingelman-Sundberg M, Sjöqvist F: Validation of methods for CYP2C9 genotyping: frequencies of mutant alleles in a Swedish population. Biochem Biophys Res Commun I999, 254:628-63I.

16. Portuguese General Directorate of Health [http:// www.dgs.pt/

17. Mota-Vieira L, Pacheco PR, Almeida AL, Cabral R, Carvalho J, Branco CC, de Fez L, Peixoto BR, Araújo AL, Mendonça P: Human DNA bank in São Miguel Island (Azores): A resource for genetic diversity studies. Proceedings of the 2 Ist International ISFG Congress 2006, I 288:388-390.

18. Portugal National Institute of Statistics [http://www.ine.pt]

19. Kumar SI, Kumar A, Srivastava S, Saraswat VA, Aggarwal R: Low frequency of factor $V$ Leiden and prothrombin G202 I0A mutations in patients with hepatic venous outflow tract obstruction in northern India: a case-control study. Indian J Gastroenterol 2005, 24:2 II-2I 5.

20. Skibola CF, Smith MT, Kane E, Roman E, Rollinson S, Cartwright RA, Morgan G: Polymorphisms in the methylenetetrahydrofolate reductase gene are associated with susceptibility to acute leukaemia in adults. Proc Natl Acad Sci USA 1999, 96: I2810-12815

21. Almawi WY, Tamim H, Kreidy R, Timson G, Rahal E, Nabulsi M, Finan $\mathrm{RR}$, Irani-Hakime $\mathrm{N}$ : A case control study on the contribution of factor V-Leiden, prothrombin G202I0A, and MTHFR C677T mutations to the genetic susceptibility of deep venous thrombosis. J Thromb Thrombolysis 2005, 19:189-196.

22. Mansilha A, Araújo F, Severo M, Sampaio SM, Toledo T, Albuquerque $R$ : Combined factor $V$ Leiden (R506Q) and prothrombin G202 I OA genotyping in young patients presenting with deep venous thrombosis. Phlebology 2006, 2 I:24-27.

23. Bauduer F, Lacombe D: Factor V Leiden, prothrombin 202 I OA, methylenetetrahydrofolate reductase $677 \mathrm{~T}$ and population genetics. Mol Genet Metab 2005, 86:91-99.

24. Arsov T, Miladinova D, Spiroski M: Factor V Leiden is associated with higher risk of deep venous thrombosis of large blood vessels. Croat Med / 2006, 47:433-439.

25. Limdi NA, Beasley TM, Allison DB, Rivers CA, Acton RT: Racial dif ferences in the prevalence of factor $V$ Leiden mutation among patients on chronic warfarin therapy. Blood Cells $\mathrm{Mol}$ Dis 2006, 37:100-106.

26. Francès F, Portolès $O$, Gabriel F, Corella D, Sorlí JV, Sabater A Alfonso JL, Guillén M: Factor V Leiden (GI69/A) and prothrombin-G202 I 0 A alleles among patients with deep venous thrombosis and in the general population from Spain. Rev Med Chil. 2006, 134(I): 13-20.

27. Ng MC, Wang Y, So WY, Cheng S, Visvikis S, Zee RY, FernandezCruz A, Lindpaintner K, Chan JC: Ethnic differences in the linkage disequilibrium and distribution of single-nucleotide polymorphisms in $\mathbf{3 5}$ candidate genes for cardiovascular diseases. Genomics 2004, 83:559-565.

28. Silingardi M, Salvarani C, Boiardi L, Accardo P, Silingardi M, Salvarani C, Boiardi L, Accardo P, lorio A, Olivieri I, Cantini F, Salvi F, La Corte R, Triolo G, Ciccia F, Ghirarduzzi A, Filippini D, Paolazzi G, lori I: Factor $V$ leiden and prothrombin gene G202 I0A mutations in Italian patients with Behcet's disease and deep vein thrombosis. Arthritis Rheum 2004, 5 I: 177-183.

29. Antoniadi T, Hatzis T, Kroupis C, Economou-Petersen E, Petersen MB: Prevalence of factor $V$ Leiden, prothrombin G202I0A and MTHFR C677T mutations in a Greek population of blood donors. Am J Hematol 1999, 6 I:265-267.

30. Hessner MJ, Luhm RA, Pearson SL, Endean DJ, Friedman KD, Montgomery RR: Prevalence of prothrombin G202I0A, factor $V$ G I 69 I A (Leiden), and methylenetetrahydrofolate reductase (MTHFR) C677T in seven different populations determined by multiplex allele-specific PCR. Thromb Haemost 1999, 81:733-738

31. Isshiki I, Murata M, Watanabe R, Matsubara Y, Kawano K, Aoki N, Yoshino H, Ishikawa K, Watanabe G, Ikeda Y: Frequencies of prothrombin 20210 G>A mutation may be different among races studies on Japanese populations with various forms of thrombotic disorders and healthy subjects. Blood Coagul Fibrinol 1998, 9:105.

32. Castro R, Rivera I, Ravasco P, Jakobs C, Blom HJ, Camilo ME, de Almeida IT: 5,10 - Methylenetetrahydrofolate reductase 677 $\mathrm{C}>\mathrm{T}$ and $1298 \mathrm{~A}>\mathrm{C}$ mutations are genetic determinants of elevated homocysteine. OJM 2003, 96:297-303.

33. Callejón G, Mayor-Olea A, Jiménez AJ, Gaitán MJ, Palomares AR, Martínez F, Ruiz M, Reyes-Engel A: Genotypes of the C677T and AI 298C polymorphisms of the MTHFR gene as a cause of human spontaneous embryo loss. Hum Reprod 2007, 22:3249-3254.

34. Coppede F, Marini G, Bargagna S, Stuppia L, Minichilli F, Fontana I, Colognato R, Astrea G, Palka G, Migliore L: Folate gene polymorphisms and the risk of Down syndrome pregnancies in young Italian women. Am J Med Genet A. 2006, I40(I 0): I083-I09I.

35. Zetterberg H, Regland B, Palmer M, Ricksten A, Palmqvist L, Rymo L, Arvanitis DA, Spandidos DA, Blennow K: Increased frequency of combined methylenetetrahydrofolate reductase $\mathrm{C677T}$ and AI 298C mutated alleles in spontaneously aborted embryos. Eur J Hum Genet 2002, 10: I I3-1 I8.

36. Shi M, Caprau D, Romitti P, Christensen K, Murray JC: Genotype frequencies and linkage disequilibrium in the CEPH human diversity panel for variants in folate pathway genes MTHFR, MTHFD, MTRR, RFCI and GCP2. Birth Defects Res A Clin Mol Teratol 2003, 67:545-549.

37. Robien K, Ulrich CM: 5, I0-Methylenetetrahydrofolate reductase polymorphisms and leukemia risk: a HuGE minireview. Am J Epidemiol 2003, I 57:571-582.

38. Sabbagh AS, Mahfoud Z, Taher A, Zaatari G, Daher R, Mahfouz RA: High prevalence of MTHFR gene AI298C polymorphism in Lebanon. Genet Test 2008, 12:75-80.

39. Bosler D, Mattson J, Crisan D: Phenotypic heterogeneity in patients with homozygous prothrombin 202 I OAA genotype. J Mol Diagn 2006, 8:420-425.

40. van Schaik RH: Dose adjustments based on pharmacogenetic of CYP450 enzymes. eJIFCC 2008, I 9:4I-46.

4I. Wu AH, Wang P, Smith A, Haller C, Drake K, Linder M, Valdes R Jr: Dosing algorithm for warfarin using CYP2C9 and VKORCI genotyping from a multi-ethnic population: comparison with other equations. Pharmacogenomics 2008, 9:169-I78.

42. Dorado P, Berecz R, Norberto MJ, Yasar Ü, Dahl ML, Llerena A CYP2C9 genotypes and diclofenac, metabolism in Spanish healthy volunteers. Eur J Clin Pharmacol 2003, 59:221-225.

43. Visser LE, van Vliet $M$, van Schaik RHN, Kasbergen AAH, De Smet PAGM, Vulto AG, Hofman A, van Duijn CM, Stricker BH: The risk of overanticoagulation in patients with cytochrome $\mathbf{P 4 5 0}$ CYP2C9*2 or CYP2C9*3 alleles on acenocoumarol or phenprocoumon. Pharmacogenetics 2004, I 4:27-33.

44. Leung A, Huang CK, Muto R, Liu Y, Pan Q: CYP2C9 and VKORCI genetic polymorphism analysis might be necessary in patients with factor $V$ Leiden and prothrombin gene G202 I A mutation(s). Diagn Mol Pathol 2007, I 6: | 84- I86.

45. Jorgensen A, Alfirevic A: Pharmacogenetics and pharmacogenomics: adverse drug reactions. Pharmacogenomics 2008 , 9:|397-|40|.

46. Yamada $Y$ : Identification of genetic factors and development of genetic risk diagnosis systems for cardiovascular diseases and stroke. Circ J 2006, 70:1240-1248. 